\title{
A survey of Malaysian Critical Intensive Care unit nurses' awareness of patients' transition experiences (PE) and transitional care practice (TCP)
}

\author{
Salizar Mohamed Ludin ${ }^{\mathrm{a}, *}$, Steve Parker ${ }^{\mathrm{b}}$, Paul Arbon ${ }^{\mathrm{b}}$ \\ a Kulliyyah of Nursing, International Islamic Malaysia, Jalan Hospital Campus, Kuantan, Pahang, Malaysia \\ b School of Nursing \& Midwifery, Flinders University, Adelaide, South Australia, Australia
}

Accepted 17 December 2013

\author{
KEYWORDS \\ Nursing; \\ Nurses; \\ Critical care nurses; \\ Critical illness; \\ Critical Intensive \\ Care Unit; \\ Transition; \\ Transitional care
}

\begin{abstract}
Summary
Background: Preparation of critically ill patients throughout their transition experiences in Critical Intensive Care Units (CICU) and following discharge can impact upon their recovery. However, there is little research addressing critical care nurses' awareness of patients' transition experiences.

Aim: This study aimed to examine CICU nurses' awareness of patients' transition experiences and transitional care practice in Malaysia.

Method: A descriptive questionnaire was used to survey Registered Nurses in seven CICUs in four hospitals in Malaysia. Data were analysed using descriptive statistics and correlation analysis. Results: The survey had a response rate of $65.2 \%$ (178 of 273 eligible nurses). The respondents' mean age was 29.6 years. Most of the respondents were from public hospitals and the majority had one to five years' experience working as Registered Nurses, and in CICU. Public teaching hospital nurses had greater awareness of patients' transition experience (PE) $(p<0.05)$, and of transitional care practice (TCP) $(p<0.05)$ than public hospital nurses. Nurses with $>10$ years Critical Intensive Care Unit experience $(p<0.05)$ had greater awareness of both PE and TCP $(p<0.05)$. Attending a course of any kind did not affect nurses' awareness in both PE and TCP $(p>0.05)$. There was a positive correlation between nurses' awareness of patients' transition experience and its impact, and their awareness of transitional care practice performance $\left(r_{s}=0.42, p<0.05\right)$.

Conclusion: CICU nurses need targeted transition education to enable them to anticipate patients' transitional experiences and to provide appropriate transitional care, particularly for public hospital nurses. Nursing schools need to integrate more content about critically ill patients' transition experiences into the curriculum, to ensure graduate nurses will be able to anticipate the patient's experience and provide appropriate transitional care.

(c) 2013 Elsevier Ltd. All rights reserved.
\end{abstract}

* Corresponding author. Tel.: +60 95706010 .

E-mail address: msalizar@iium.edu.my (S.M. Ludin).

0964-3397/\$ - see front matter @ 2013 Elsevier Ltd. All rights reserved.

http://dx.doi.org/10.1016/j.iccn.2013.12.006 


\section{Implications for Clinical Practice}

- There is a need for more and ongoing nurse education about patients' transition experience and transitional care practice, particularly for public hospital nurses. The education can be given through in-service education organised by hospital management or through short programmes organised by nursing schools.

- Preparation of future nurses can be strengthen through nursing schools by integrating more content about critically ill patients' transition experiences into the curriculum, to ensure graduate nurses will be able to anticipate the patients' experience and provide appropriate transitional care.

\section{Introduction}

Critically ill patients recovering from critical illness often suffer lasting physical and psychological effects; they generally require a package of care to support their complex needs as part of their recovery to good health or to a near normal condition (Foust, 2007). Transfer to a general ward after severe critical illness or with consequential problems can be distressing and challenging. Hence, appropriate preparation of patients throughout their health and illness transitions is a vital aspect of recovering from critical illness.

\section{Aim}

This study aimed to examine Critical Intensive Care Unit (CICU) nurses' awareness of patients' transition experiences and transitional care practice in Malaysia.

\section{Materials and methods}

\section{Literature review}

A literature search of CINAHL, MEDLINE, OVID, Science Direct, SAGE eReference and SAGE Journal Online data bases, using the keywords transition, transition experience, transitional care, transfer, critically ill, critical/intensive care patients' and nurses perspectives in various combinations revealed limited literature addressing the concept of transition linked to nursing care. This is surprising considering the concept of transition from CICU to other settings. The focus of transition is on the individual and how they cope with the experience of clinical care; as such it is central to nursing care processes (Chick and Meleis, 1986, p. 239; Meleis and Trangenstein, 1994; Meleis et al., 2000). Chick and Meleis (1986, p. 239) define transition as a passage from one life phase, condition or status to another...both the process and the outcome of complex person-environment interaction which is most pertinent to the critical care envronment. Nevertheless, critically ill patients' transition in the Critical and Intensive Care Units are generally described as a period of transfer or change of situation, or the experience of inner change or role during and after the illness. The critically ill patients' transition experience per se is not directly described, nor is nurses' understanding of it (Salizar et al., 2013).

Nurse-client encounters during transitional periods of instability, which can be precipitated by developmental, situational or health-illness changes and, which may produce profound alterations in the lives of individuals and their significant others, have important implications for well-being and health (Schumacher and Meleis, 1994). Nurse-client encounters are particularly frequent and important in the case of critically ill patients who make several transitions across care settings during their recovery or towards palliative care (Chaboyer et al., 2005). Each transition poses unique challenges for patients, families and health care professionals involved in patients' care (Chaboyer et al., 2005). Nurses play an important role in preparing the patients and families to cope with the changes in care settings and the different levels of care (Chaboyer et al., 2005). As such they should be able to provide proper planning and care interventions in response to patients' transition needs. Thus, discharge planning from CICU is a crucial part of transitional care.

Nurses in Australian Critical Intensive Care Units have identified that discharge planning is not one of their responsibilities (Watts and Gardner, 2005). In this study most nurses appeared to have a lack of understanding of what discharge planning means and defined the discharge planning process only in relation to planning and organising. The researchers also reported that participants showed only scant knowledge of key elements concerning education and family involvement, with emphasis instead on preparation of patients for discharge from the critical care unit to general wards. Hence the nurses in this study were meeting the immediate care needs only in relation to transition from intensive care, perhaps explaining why they perceive that discharge planning - which they relate to hospital discharge - is not one of their responsibilities.

This finding is consistent with Chaboyer et al. (2004) and Salizar (2011), who that found that decisions for discharge planning for ICU patients were often deferred, because anticipating post-intensive care needs can be difficult for patients with high acuity and uncertain recovery. Furthermore, nurses reported limited time to spend on discharge planning and lack of knowledge and skills about discharge planning. In contrast to these finding, a pilot study by Holland et al. (2012) found that discharge planning is feasible in intensive care units. This was identified by showing that more than half $(55 \%)$ of patients' self-care deficits presenting at hospital discharge were in fact identified within 24 hours of admission to the intensive care unit. This indicates that ICU nurses can and do contribute to preliminary identification of post-acute care needs.

It is surmised that a similar situation may be evident in Malaysian intensive care units but to date, nurses' awareness of critically ill patients' transition experience and nurses' responsibilities in discharge planning from intensive care is not well understood in that country. A specific search of Malaysian Health documents (Salizar, 2011) shows that although the Ministry of Health of Malaysia directs the 
Malaysian health care system, there appears to be no specific national or local policy related to critically ill patients' transition experience and transitional care. The Ministry of Health regulations concerning awareness and anticipation of the effects of transition stipulate that care should be provided before, during and after transfer and discharge from health care settings. However, whilst work-based instruction manuals and specific unit-based documentation for intensive care areas provide general guidelines for patients' transfer and discharge, they are designed mainly to enhance nurses' awareness and monitoring of patients' transition experience only in terms of location change and health-illness transition.

It appears therefore, that despite acknowledging the term 'transition', it is assumed to be a process (mainly a changing stage of the patients' situation, in this case in the health-illness stage) as well as an action or movement from one physical situation to another (Chaboyer et al., 2005; Salizar, 2011). Documentation in the form of check lists (such as orientation, rehabilitation and health education checklists) reflects the Malaysian health system's definition of transition as a phenomenon that occurs when trying to meet the challenge of caring for patients when moving them into a strange environment (Salizar, 2011). Thus care and awareness of practice related to transfer and discharge of patients are consistent with the 9th Malaysia Plan (EPU, 2006), which aims to prevent and reduce the burden of disease and enhance the health delivery system. However, the focus is on monitoring and assessing the patients' health-illness transition to ensure safety and quality care; there is no specific focus on the patients' transition experiences. This needs to be addressed because there is evidence that post-Critical Intensive Care Unit patients suffer from a variety of physical and psychological problems (Chaboyer et al., 2005; Kelly and McKinley, 2010).

Critical illness survivors have reported problems during recovery. In particular alterations in physical function may result from traumatic injury or debilitating effects of an illness itself, manifesting as muscle weakness, recurring pain, sleep difficulties, polyneuropathies, poor appetite, voice and taste changes all of which can reduce overall functional capacity (Needham, 2008; Richman, 2000). These observations can be supported by Kelly and McKinley's (2010) study on patients' recovery after critical illness at early followup. They have found that critical illness survivors, despite perceiving their general health as good, nevertheless experienced significant physical and psychological limitations during recovery. This effect can be manifest after discharge and therefore, ICU nurses are in a very good position to help patients/families to prepare or minimise this limitation.

The above findings show that nurses' awareness of the critically ill patients' transition experience is important to address prior to discharge from the intensive care environment. Nevertheless, despite theoretical arguments and evidence suggesting the importance of understanding $\mathrm{CICU}$ patients' transition experiences, to date the general literature and Malaysian health care documentation have not clearly identified or discussed nurses' awareness of these experiences. Most literature focuses on transitions of a patient's condition, role and care as they are moved to other locations (Marineau, 2005; Soanes and Timmons, 2004). Thus this study aims to explore CICU nurses' awareness of patients' transition experiences with the following objectives.

\section{Research objectives}

1. To determine CICU nurses' awareness of patients' transition experiences $(\mathrm{PE}) \mathrm{s}$, and of transitional care practice (TCP);

2. To examine the relationship between CICU nurses' characteristics and awareness of PE and TCP.

It also sought to test two hypotheses related to the second research objective:

1. Nurses' awareness of patients' transition experience (PE) and transitional care practice (TCP) is related to types of hospital, $\mathrm{CICU}$ working experience and intensive care course completion.

2. Nurses' awareness of patients' transition experience PE is related to their awareness of transitional care practice (TCP).

\section{Ethical considerations}

Approval for the study was obtained from Flinders University, Directors of the participating hospitals, the Prime Minister's Department, Malaysia and the National Medical Research Ethics Committee of Malaysia. Ethical issues were repeatedly revisited during the study to ensure that respondents' rights were protected. Respondents were provided with information regarding the study's purpose, research procedures, assurance of confidentiality and statements about their right to withdraw at any time. The return of the completed questionnaire was treated as informed consent to participate.

\section{Design and setting}

A descriptive survey using a questionnaire was distributed to a purposive sample of CICU nurses working in seven CICU's, which in turn are situated in four public tertiary hospitals in metropolitan areas in the Klang Valley, Malaysia, over a seven-month period. The survey was designed so that the nurses could self-administer it in their own time and place. Self-administration was chosen as a method for gaining more participants as the questionnaire can be distributed to many participants and they can complete and return the survey at their own convenient time (Polit and Beck, 2004).

\section{Participants and sampling}

Inclusion criteria for participation in the study were that participants must be Registered Nurses who had worked full time for a minimum of six months in the CICU; must understand English; must have a minimum of a diploma level education (basic qualification); and may or may not have attended advanced diploma courses. The inclusion criteria were designed to distinguish the influence of participants' characteristics on the study's objectives, as it has been shown that nurses' education levels and experience can have an impact upon the effectiveness of their knowledge, attitudes and clinical practice (Aiken et al., 2003, 


\section{Survey tool}

2012; Blegen et al., 2001; Clare and Hofmeyer, 1996). In the study reported on here, the researcher believed that nurses meeting the stated criteria would provide the most realistic presentation of bedside CICU nurses' perspectives of the transition experiences of patients. All nurses in the seven CICU's from the four participating hospitals were invited to participate. They received the questionnaire during handover time on their units.

The sample size was calculated using the Raosoft Sample Size Calculator (Raosoft, 2004). Based on a population of 273 nurses and an anticipated response rate of $50 \%$, the research team concluded that a sample size of 160 (58.6\%) was considered appropriate to provide sufficient power $(\beta=0.9)$ with a confidence level of $95 \%$ and a $5 \%$ error margin.
A new questionnaire was designed as the survey tool for the study because current tools were not specific to measuring nurses' awareness of patents' transition experiences. The new tool contained closed- (pre-coded) and open-ended questions that allowed participants to state their answers in their own words. Section A contained eight pre-coded, alternative response nurse profile questions related to age, type of hospital and the unit in which they were working, years of working experience, nursing qualifications and post-diploma courses attended.

Sample Question from Section A:

Please specify your age in years

Please indicate the hospital you are currently working:

Ministry of Health hospitals (Public) Ministry of Higher Education (Teaching)

Sections $B$ and $C$ contained 35 response items in eight closed-ended questions, which made up the scale for nurses' Sample Questions from Section B: awareness of patients' transition experience (PE).

\begin{tabular}{|c|c|c|c|c|c|}
\hline \multicolumn{6}{|c|}{ Strongly believe(SB), Believe(B), Not sure(NS), Disbelieve (DB), Strongly disbelieve (SDB) } \\
\hline $\begin{array}{l}\text { 8. This question is focusing on transition. Which of the followings do you believe is } \\
\text { 'transition'? }\end{array}$ & SB & B & NS & DB & SDB \\
\hline a. Movement of the patient between two points (care settings) & 5 & 4 & 3 & 2 & 1 \\
\hline $\begin{array}{l}\text { b. A process in which involves transformation or alteration of condition, needs or } \\
\text { situation }\end{array}$ & 5 & 4 & 3 & 2 & 1 \\
\hline c. A process of inner-reorientation as the person learns to adapt and incorporate & 5 & 4 & 3 & 2 & 1 \\
\hline
\end{tabular}

Sample Questions from Section C:

\begin{tabular}{|c|c|c|c|c|c|}
\hline $\begin{array}{l}\text { 13. Transition may influence the patients and care needs. How concerned are you } \\
\text { about these impacts? }\end{array}$ & MC & C & NS & LC & NCA \\
\hline a. Being critically ill and needing intensive care & 5 & 4 & 3 & 2 & 1 \\
\hline b. Unable to anticipate the effects of transition & 5 & 4 & 3 & 2 & 1 \\
\hline c. Feelings of vulnerability when transferred or discharged & 5 & 4 & 3 & 2 & 1 \\
\hline d. Coping with alteration in mobility and function & 5 & 4 & 3 & 2 & 1 \\
\hline e. Feeling anger, withdrawal and anxiety about transfer/discharge & 5 & 4 & 3 & 2 & 1 \\
\hline f. Relocation stress due movement to another care setting & 5 & 4 & 3 & 2 & 1 \\
\hline g. Delayed recovery due prolonged illness & 5 & 4 & 3 & 2 & 1 \\
\hline h. Financial difficulties due to prolonged illness & 5 & 4 & 3 & 2 & 1 \\
\hline
\end{tabular}


Section D consisted of 74 response items contained in 19 questions, some of which were closed questions and some of which were open-ended. These questions made up the scale for nurses' awareness of transitional care practice (TCP).

for nurses' awareness of transitional care practice (TCP).
\begin{tabular}{|l|l|c|c|}
\hline 17 & How did you gain knowledge about Transitional Care? & YES & NO \\
\hline a & Nursing School & 2 & 1 \\
\hline b & In-service education & 2 & 1 \\
\hline c & Own reading & 2 & 1 \\
\hline d & Never learned before & 2 & 1 \\
\hline e & On the job training & 2 & 2 \\
\hline
\end{tabular}

The tool's total possible lowest-highest score for awareness of PE is 35-175. The possible lowest-highest score for awareness of TCP is 72-344. The design of the questionnaire allowed for clarity of questions being asked and for ease of response. The rationale here was to encourage participation by providing participants with an estimated time for completion that would assure them that the questionnaire could be completed, without too much time being needed.

A Pilot Study was completed by sending the questionnaire to ICU experts for content validity testing. This systematic examination determined whether the content covered a representative sample of the behavioural domain to be measured (Anastasi and Urbina, 1997). Face validity was also tested on 25 similar participants. Alterations were made in light of feedback from the Pilot Study, such as changing the questions that were considered too ambiguous. This formed the final version of the questionnaire for distribution to participants.

\section{Data collection}

The researcher made arrangements with the participating hospitals and Critical Intensive Care Units to talk to the nurses about the study after hand-over-meetings and to invite them to participate. Nurses who volunteered to participate were given stamped, pre-addressed envelopes containing the self-administered questionnaire and information on how to return it.

\section{Data analysis}

Data collected from the four hospitals were pooled for analysis using the Statistical Package for Social Sciences (SPSS version 17). Descriptive analysis, including means and percentages, was undertaken first to summarise demographic profiles and transition awareness data.

Non-parametric testing was then undertaken to test the two hypotheses related to the second research question. The Mann-Whitney $U$ test was used to examine the relationship between the nurses' characteristics and PE and TCP, and the Spearman Rank Correlation test was used to examine the relationship between PE and TCP. The level of significant was set at $p=0.05$.

\section{Results}

\section{Sample characteristics}

The sample consisted of 178 nurses from a total of $273 \mathrm{CICU}$ nurses (from three public hospitals and one public teaching hospital), achieving a response rate of $65.2 \%$; 130 (73\%) from public hospitals and 48 (27\%) from public teaching hospitals (The breakdown of participants' responses based on the type of hospital is shown in Table 1) and nurses had a mean age of 29.6 years (SD 6.81) (range, 22-53 years) (see Table 2).

All participants had the minimum qualification (diploma) required for participation. The majority had one to five years Registered Nurse working experience and had between one to five years of experience working in CICU $(60.1 \%$, $64 \%)$. Only 66 nurses $(37.1 \%)$ had undertaken a course during their nursing service, of whom $25(14 \%)$ completed a Coronary Care course and another 41 (23\%) completed a Critical Care or Intensive Care course (Table 1). It is possible to hypothesise about the characteristics of the nurses who chose not to participate based on the breakdown of nurses in each hospital that involved but not for the reasons why some chose to participate and others did not.

Table 1 Breakdown of response rate based on total number of sample in each participating hospital.

\begin{tabular}{llccl}
\hline Hospital & Type & Q distributed & Returned forms & $\%$ response rate \\
\hline $\mathrm{H} 1$ & MOH & 100 & 62 & $62 \%$ \\
$\mathrm{H} 2$ & $\mathrm{MOH}$ & 56 & 25 & $44.6 \%$ \\
$\mathrm{H} 3(1)$ & $\mathrm{MOHE}$ & 26 & 24 & $50 \%$ \\
$\mathrm{H} 3(2)$ & & 26 & 24 & $92.3 \%$ \\
$\mathrm{H} 4$ & $\mathrm{MOH}$ & 45 & 43 & $97.77 \%$ \\
& Total & 273 & 178 & Response rate 65.2\% \\
\hline
\end{tabular}


Table 2 Participants' demographic characteristics $(N=178)$.

\begin{tabular}{|c|c|c|c|}
\hline \multicolumn{4}{|l|}{ Demographic characteristics } \\
\hline & & Frequency & $\%$ \\
\hline \multirow[t]{2}{*}{ Q2 - Hospital currently working } & $\mathrm{MOH}$ & 130 & $73.0 \%$ \\
\hline & MOE & 48 & $27.0 \%$ \\
\hline Q3 - Highest nursing qualification & Diploma & 178 & $100.0 \%$ \\
\hline \multirow[t]{5}{*}{ Q4 - Working experience as registered nurse (years) } & Less than 1 year & 2 & $1.1 \%$ \\
\hline & $1-5$ years & 107 & $60.1 \%$ \\
\hline & $6-10$ years & 40 & $22.5 \%$ \\
\hline & $11-15$ years & 15 & $8.4 \%$ \\
\hline & More than 15 years & 14 & $7.9 \%$ \\
\hline \multirow[t]{5}{*}{ Q5 - Working experience as registered nurse in the current C/ICU (years) } & Less than 1 year & 2 & $1.1 \%$ \\
\hline & $1-5$ years & 114 & $64.0 \%$ \\
\hline & $6-10$ years & 39 & $21.9 \%$ \\
\hline & $11-15$ years & 12 & $6.7 \%$ \\
\hline & More than 15 years & 11 & $6.2 \%$ \\
\hline \multirow[t]{2}{*}{ Q6 - Indicate whether you have completed any critical/intensive Care course } & No & 112 & $62.9 \%$ \\
\hline & Yes & 66 & $37.1 \%$ \\
\hline \multirow[t]{4}{*}{ Q7 - Specify the Critical/intensive care course that you have completed } & No course completed & 112 & $62.9 \%$ \\
\hline & $\mathrm{CCU}$ & 25 & $14.0 \%$ \\
\hline & CICU & 0 & $.0 \%$ \\
\hline & $\mathrm{C} / \mathrm{ICU}$ & 41 & $23.0 \%$ \\
\hline
\end{tabular}

$\mathrm{MOH}$ - Ministry of Health Malaysia - public hospital; MOE - Ministry of Education - public teaching hospital; CCU - Coronary Care Unit Course; C/ICU - Critical \& Intensive Care Unit Course; CICU - Cardiothoracic \& Intensive Care Unit Course.

\section{Relationship between nurses' characteristics and 'Total awareness of patients' transition experience (PE)' and 'Total awareness of transitional care practice (TCP)'}

Data related to the two variables PE and TCP were compared in terms of hospital type (public or public teaching hospital). There was a statistically significant difference between hospital types for both variables. Teaching hospital nurses had greater awareness of PE $(z=-4.941, p<0.05)$ and TCP $(z=-5.116, p<0.05)$ than public hospital nurses (Table 3$)$.

In terms of nurses' years of CICU experience, the categories of variables were collapsed and recoded $(<10$ years and $>10$ years). These categories were chosen based on the research evidence which has shown a positive correlation between nurses' experience and knowledge (awareness). The findings show that the more years of experience the CICU nurses had, the more exposure and knowledge (awareness) they had of critically ill patients' situations and, in the quality of care they may provide. Consistently, there was a statistically significant difference between these two groups. Participants with $>10$ years $\mathrm{CICU}$ experience had significantly higher PE than those with $<10$ years of this experience $(z=-3.188, p<0.05)$. This may indicate that the length of CICU experience influenced participants' understanding of patients' transition experiences. There was a statistically significant difference in the 'Total Awareness of TCP between categories of experience as a CICU nurse. Participants who had $>10$ years' of experience had higher TCP than $<10$ years $(z=-2.082, p<0.05)$. This indicates that nurses' length of experience in Critical Intensive Care Units affects their awareness of transitional care practice performance (Table 3).
There was no statistically significant difference in the results for PE or TCP between nurses who had completed a specialised course and those who had not $(z=-0.457$, $-0.289 ; p>0.05)$. This suggests that there was no relationship between the participants' level of transitional care practice performance or patients' transition experience and specialised course completion (Table 3).

\section{Relationship between 'patients' transition experience (PE)' and 'transitional care practice (TCP)'.}

The result from the Spearman's Rank Correlation test shows a statistically significant relationship between the participants' awareness of PE and TCP $\left(r_{s}=0.42, p<0.05\right)$. The result indicates a positive correlation between the two variables; the higher the value for PE, the higher the value for TCP.

\section{Discussion}

Analysis of the literature, including the Malaysian Health documentation, points to the need for a transition theory framework to facilitate an understanding of $\mathrm{CICU}$ patients in health care transitions and their access to the help they need to cope with the ordinary, and extraordinary, processes of living (Chaboyer et al., 2005; Salizar, 2011; Salizar et al., 2013). Such a framework may also be helpful in planning and providing more appropriate nursing interventions for patients experiencing transition.

The survey data analysis suggests that Malaysian CICU nurses' awareness of critically ill patients' transition 
Table 3 Relationship between CICU nurses' characteristics and patients' transition experience (PE) and transitional care practice (TCP).

\begin{tabular}{|c|c|c|c|c|c|c|c|c|}
\hline \multirow[t]{2}{*}{ Variable } & & \multirow[t]{2}{*}{$N$} & \multicolumn{3}{|l|}{ PE } & \multicolumn{3}{|l|}{ TCP } \\
\hline & & & Mean rank & Z score & $p$ value & Mean rank & Z score & $p$ value \\
\hline \multirow[t]{2}{*}{ Hospital } & $\mathrm{MOH}$ & 130 & 77.92 & -4.941 & $<0.001^{*}$ & 77.5 & -5.116 & $<0.001^{*}$ \\
\hline & MOE & 48 & 120.88 & & & 122.01 & & \\
\hline \multirow[t]{2}{*}{ Experience as $\mathrm{CICU} \mathrm{RN}$} & $<10$ years & 155 & 84.76 & -3.188 & $0.001^{*}$ & 86.4 & -2.082 & $0.037^{*}$ \\
\hline & $>10$ years & 23 & 121.43 & & & 110.37 & & \\
\hline \multirow[t]{2}{*}{ Specialized course completion } & Yes & 112 & 90.85 & -.457 & 0.648 & 88.62 & -0.298 & 0.766 \\
\hline & No & 66 & 87.2 & & & 91.0 & & \\
\hline
\end{tabular}

$\mathrm{PE}$ - patients' transition experience; TCP - transition Care Practice; $\mathrm{MOH}$ - Ministry of Health Malaysia - public hospital; MOE - Ministry of Education - public teaching hospital; ICU - Intensive Care Unit; RN - Registered Nurse.

" $p<0.05-$ is significant.

experience is associated significantly with the type of hospital in which they work, thus supporting this part of hypothesis 1 . Despite the small number of nurses from teaching hospitals, as only one teaching hospital was involved in the study as compared to three public hospitals involved, participants from the teaching hospital are more aware of critically ill patients' transition. This result may be due to the teaching hospitals' commitment to teaching and learning for their staff, which equips their nurses with a solid educational foundation that influences their understanding of patients' experiences, including the experiences and impacts of transition, and may also enhance their care performance over time.

The results related to the effect of the number of years of nursing experience ( $<10$ years or $>10$ years) in $\mathrm{CICU}-$ length of time did correlate with a greater awareness of the transitional care practice provided. Data indicate that the number of years of experience may create a difference in nurses' transitional care practice performance, thus supporting this part of hypothesis 1 . This result is consistent with previous study findings (for example Aiken et al., 2003; Blegen et al., 2001) which indicate that the more experienced nurses provide higher-quality care. It should be noted, that $>10$ years of experience in Malaysian Critical Intensive Care Units influenced participants' understanding of patients' transition experience, thus supporting this part of hypothesis 1 .

In relation to the results regarding whether or not participants had completed a specialised course (not necessarily in CICU patient transition), the lack of any significant difference did not support this part of hypothesis 1 . The finding may indicate that knowledge of transition could have been left out from the course. Otherwise, the small number of nurses within the study sample who had completed a special course raises the question of whether the comparison can be considered valid. This result must be treated with caution.

The positive correlation between 'Total awareness of patients' transition experience (PE) and 'Total awareness of transitional care practice' (TCP) implies that the more aware the participants are of transition and its impact on patients' experiences, the more aware they will be in their transitional care practice. This result leads the researcher to claim that the increased level of awareness (knowledge on transition) may increase their level of expectation and self-preparation for good performance.

When considering this finding in conjunction with the results for years of experience and comparison across the two hospital types, it would appear that education may be a defining factor. In other words, nurses' experience and education in a teaching environment (teaching hospital) can impact positively upon their quality of care. This is supported by Aiken et al. (2003). At the same time it should be considered that other research has not indicated significant differences between nurses' quality of care with differing education levels Blegen et al. (2001).

Comparing the survey results with the Malaysian Health documentation (Salizar, 2011) searched as part of the literature review, the nurses' awareness in this study seems to be consistent with the hospital expectation for patients' transition and care. That is, ensuring that the patients are safe and receive quality care. The documents analysed provide information on the health organisations' knowledge of transition as health-illness transition and situational transition as a result of critical illness. The policy for patients during the transition period is named as 'transfer/discharge' policy, although the tasks expected of the employees focus also on monitoring and assessing patients' health-illness transition. Despite this focus, there was a lack of information on the patients' and their family members' abilities to cope and adapt with transition and nurses required knowledge and action during critical illness. Hence, a deeper exploration of health organisations' knowledge and the nurses' actual experience, or any concerns related to their experience is needed.

Despite the small sample size, the findings as a whole show that $\mathrm{CICU}$ nurses did see the relevance of their role in patients' transition experiences. They view transition not just as moving from one setting to another, but also as changes in health status and experience during illness; which is still within the context of discharge planning from ICU. This is contradicted within the study findings by Watts and Gardner (2005) as explained in the literature review. More research is needed specific to Critical Intensive Care Unit nurses' awareness of critically ill patients' transition experiences in relation to what it is like to be in the transition phenomena - the ongoing journey and its consequences for 
the patients and family members and the effect of this on the nurses' performance of transitional care practice.

\section{Limitations}

The small sample size and limited geographical distribution limit generalisability of the results. The reliability and validity of the new scales and context suitability of the questions in the new survey tool may be questioned as it has never been used in any other study before; the results could be biased as the meaning of question could be understood differently (communication barriers between researcher and participants). In terms of the sample, using the five year benchmarks might have been better (rather than 10 years) as this could have provided more scope for analysis within the study. Furthermore, although the number of nurses who participated is 178 (65\%), the non-teaching hospitals were more represented (as three non-teaching hospitals were involved in the study, as opposed to only one teaching hospital). This may affect the validity of the study and this is something to consider for future research.

\section{Conclusion}

The results imply the need for more and ongoing nurse education about patients' transition experience and transitional care practice, particularly for public hospital nurses in Malaysia. The implication is that nursing schools need to integrate more content and need to be more transparent about critically ill patients' transition experiences in the curriculum (basic and advance courses) to ensure graduate nurses will be able to anticipate patients' experiences and provide appropriate transitional care. The findings as a whole show that CICU nurses in Malaysia did see the relevance of their role in patients' transition and they view transition as outside the context of discharge from ICU. There is also a need for further research into the development and validation of proper scales to measure the level of awareness of patients' transition experience among nurses, patients and their family members.

\section{References}

Aiken LH, Clarke SP, Cheung RB, Sloane DM, Silber JH. Educational levels of hospital nurses and surgical patient mortality. JAMA 2003;290(12):1617-23.

Aiken LH, Van den Heede K, Sloan DM, Busse R, McKee M, Bruynee $L$, et al. Patient safety, satisfaction, and quality of hospital care: cross sectional surveys of nurses and patients in 12 countries in Europe and the United States. BMJ 2012;344:e1717, http://dx.doi.org/10.1136/bmj.e1717 (published 20.03.12).
Anastasi A, Urbina S. Psychological testing. Upper Saddle River, NJ: Prentice Hall; 1997.

Blegen MA, Vaughn T, Goode CJ. Nurse experience and education: effect on quality of care. JONA: The Journal of Nursing Administration 2001;31(January (1)):33-9.

Chaboyer W, Foster M, Kendall E, James H. The impact of a liaison nurse on ICU nurses' perceptions of discharge planning. Australian Critical Care 2004;17(1):25-32.

Chaboyer W, James H, Kendall M. Transitional care after the intensive care unit. Critical Care Nurse 2005;25(June (3)):16-28.

Chick N, Meleis Al, editors. Transition: a nursing concern. Nursing Research Methodology. Boulder, CO: Aspen Publication; 1986.

Clare J, Hofmeyer A. Towards seamless health care: aged people, their carers and discharge planning in a Casemix environment. South Australia: Flinders University; 1996.

EPU. 9th Malaysia Plan, Economic Planning Unit, Prime Minister's Department, Malaysia; 2006 http://www.epu.jpm.my/ rm9/english/Chapter20.pdf [retrieved 1.08.07].

Foust JB. Discharge planning as part of daily nursing practice. Applied Nursing Research 2007;20(2):72-7.

Holland DE, Rhudy LM, Vanderboom CE, Bowles KH. Feasibility of Discharge Planning in Intensive Care Units: A Pilot Study. Am J Crit Care 2012;21:e94-101, http://dx.doi.org/10.4037/ajcc2012173.

Kelly MA, McKinley S. Patients' recovery after critical illness at early follow-up. Journal of Clinical Nursing 2010;19:691-700.

Marineau M. Health/Illness transition and telehealth: a concept analysis using an evolutionary method. Nursing Forum 2005;40(July-September (3)):96.

Meleis Al, Sawyer L, Im E-O, Hilfinger M, DeAnne K, Schumacher K. Experiencing transitions: an emerging Middle-Range Theory. Journal of Advanced Nursing 2000;23(1):12-28.

Meleis Al, Trangenstein PA. Facilitating transitions: redefinition of the nursing mission. Nursing Outlook 1994;42:255-9.

Needham DM. Mobilizing patients in the Intensive Care Unit: improving neuromuscular weakness and physical function. Journal of American Medical Association 2008;300:1685-90.

Polit DF, Beck CT. Nursing Research. Principles and Methods. 7th edition Philadelphia: Lippincott Williams \& Wilkins; 2004.

Richman J. Coming out of intensive care crazy: dreams of affliction. Qualitative Health Research 2000;10:84-102.

Raosoft. Sample size calculation; 2004 http://www.raosoft.com/ samplesize.html [retrieved 01.08.07].

Salizar ML. [unpublished Ph.D. thesis] Critically ill patients' transition: Malaysian ICU nurses' perspectives [unpublished Ph.D. thesis]. Adelaide: Flinders University; 2011.

Salizar ML, Arbon P, Parker S. Patients' transitions in the intensive care unit: a concept analysis. Intensive \& Critical Care Nursing Journal 2013;29:187-92.

Schumacher KL, Meleis Al. Transitions: a central concept in nursing. IMAGE: Journal of Nursing Scholarship 1994;26(2):119-27.

Soanes C, Timmons S. Improving transition: a qualitative study examining the attitudes of young people with chronic illness transferring to adult care. Journal of Child Health Care 2004;8(2):102-12.

Watts R, Gardner H. Nurse perceptions of discharge planning. Nursing and Health Sciences 2005;7:175-83. 